\title{
Exploring the Potential of Blended Learning to Promote Retention and Achievement in Higher Education Professional Study Programs
}

\author{
Josianne Basque and Béatrice Pudelko \\ LICEF Research Center \\ Télé-université (TÉLUQ) \\ Montreal, Canada \\ basque.josianne@teluq.uqam.ca \\ pudelko.beatrice@teluq.uqam.ca
}

\begin{abstract}
In this paper, we present a blended learning model designed for a university professional study program attended by full-time professional workers, i.e. in-service teachers studying in the field of School Administration. The model integrates four main instructional strategies at the program level: mentoring; participation in an online community of professional learning and practice; collaborative concept-mapping with an objecttyped knowledge modeling software, and face-to-face seminars in a work setting. Based on interview and observation data collected during two successive small-scale experimentations of the model, we explored potential factors that could have had an impact on students' academic retention and achievement. Four types of factors were identified: personal, professional, institutional and pedagogical. We found that pedagogical and professional factors, which are insufficiently considered in theoretical models of student retention, are of primary concern for students who work full-time as professionals. A blended learning model designed at the program level and strongly "situated" in the professional practice of the students is a promising avenue to adjust to their career constraints and aspirations and, thus, promoting their academic retention and achievement.
\end{abstract}

Keywords - Blended Learning, Professional Learning, Curriculum Design, Student Retention, Non-Traditional Students, Design-Based Research.

\section{INTRODUCTION}

During the last two decades, professional study programs have been multiplying in universities in response to the growing demand by the Knowledge Society for highly skilled workers and life-long learners [1,2]. Many of these programs are primarily attended by non-traditional students who are older than traditional students, who have a professional, as well as a marital and family life and whose study goals are strongly focused on career aspirations and on the development of their professional competencies.

The ever-increasing enrolment of this student population in universities represents a great challenge in terms of student retention and academic success. Models of retention which put great emphasis on the academic integration of students [e.g. 3]) are not suited to this population because they do not sufficiently take into account its specific personal and professional needs and constraints [4,5,6,7]. Pedagogical factors and university teaching structures, in particular, may have a significant influence on the academic achievement and retention of these students $[8,9]$. For example, long-established campus-based courses and a traditional pedagogy inadequately related to real-world professional practices may be substandard for these types of students [10]. As stated by Voorhees [11], there is a need for a "fundamental reengineering of current delivery systems, inviting debate about the traditional academic structure, the standard length of academic terms, and the very process for certifying student learning" (p. 11). From that viewpoint, blended learning, which combines computermediated and face-to-face instruction [12] may be a promising avenue.

Throughout a four-year research project, we were part of a research team that addressed the issue of how to promote retention and achievement in university professional study programs attended by working full-time professional workers. More specifically, the objectives of the project were threefold: (1) develop a blended learning model at the program level which aims to promote student retention and success in these types of program; (2) implement the model in a specific study program and analyze conditions of successful implementation; (3) explore factors that may support or hinder students' retention and success in the program.

In this paper, we will first describe the pedagogical scenario of the blended learning model (section II) and secondly, the learning environment developed in support of this scenario (section III). In section IV, we outline the research methodology of the project. Some results related to the third objective of the study are reported in section $\mathrm{V}$.

\section{THE BLENDED LEARNING SCENARIO}

Based on socio-constructivist, situated and experiential learning theories $[13,14]$, the research team developed a learning model which closely integrates four main instructional strategies at the program level: (1) mentoring of students by experienced work colleagues, (2) participation in an online 
Community of Professional Learning and Practice (CPLP) [15, 16], (3) collaborative concept-mapping [17], consisting at constructing a node-link representation of knowledge related to the students' work practice, (4) face-to-face seminars in the students' work setting. Our goal was to make students cognitively active and reflexive learners, as well as progressively legitimate participants in their community of professional practice $[18,19]$.

We put in place an integrated curriculum approach strongly linked to the students' professional activities, which is structured according to the four phases of Kolb's experiential learning cycle [14] rather than according to isolated course units as it is generally the case in regular programs. ${ }^{1}$ Figure 1 illustrates this structure and Table 1 describes in more detail each instructional strategy included in the model. Several experiential learning cycles can be implemented throughout a study program. For example, a new experiential learning cycle could start every one or two months.

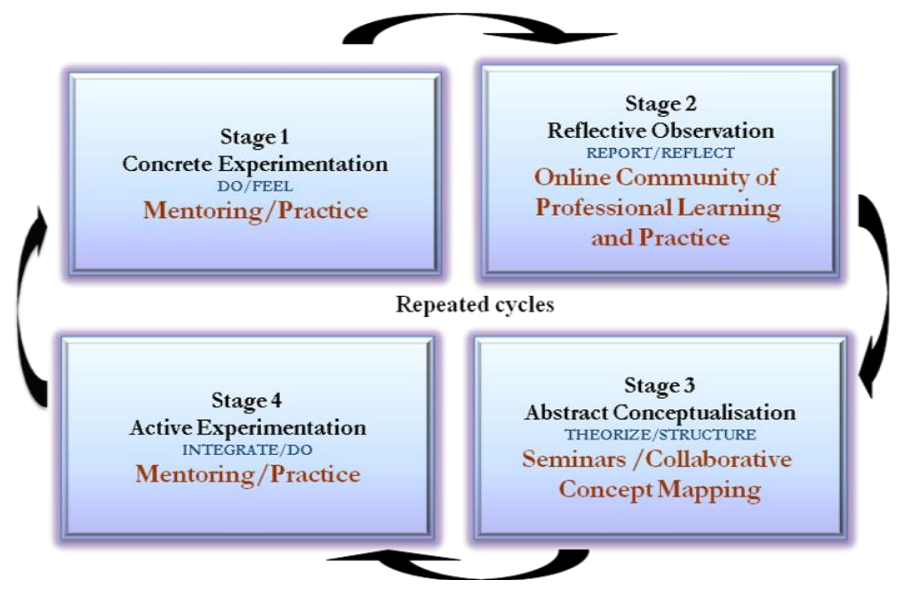

Figure 1. The experiential learning cycle implemented in the model

\section{THE BLENDED LEARNING ENVIRONMENT}

One important decision we made regarding the learning environment supporting the proposed pedagogical scenario was to develop a single website for the whole program, where students would have access to various documents describing the program and to learning resources related to each instructional strategy, as well as share ideas and productions in a virtual forum. Each instructor could add learning resources to the program website at any time. We also stated that the program website could be hosted in any existing e-learning platform.

For the collaborative concept mapping activity, our previous work on knowledge modeling for learning [20, 21] led us to recommend the use of the object-typed knowledge modeling software MOTplus ${ }^{2}$, developed by Paquette and his team at the LICEF Research Center (Montreal, Canada) [22].

${ }^{1}$ We did, however, have to respect the institutional rules for student grading. Grades were attributed on a course basis, as it is the case in the regular version of the study program.

${ }^{2}$ MOT is a French acronym that stands for Modélisation par Objet Typé (Object-Typed Modeling).
TABLE I. DESCRIPTION OF THE BLENDED LEARNING MODEL

\begin{tabular}{|c|c|c|c|}
\hline $\begin{array}{c}\text { Experiential } \\
\text { Learning } \\
\text { Stages }\end{array}$ & $\begin{array}{l}\text { Instructional } \\
\text { Strategy }\end{array}$ & Modality & Description \\
\hline \begin{tabular}{|l} 
Stage 1 \\
Concrete \\
Experience \\
(Do/Feel)
\end{tabular} & $\begin{array}{l}\text { Practice and } \\
\text { Mentoring }\end{array}$ & $\begin{array}{l}\text { Face-to- } \\
\text { face }\end{array}$ & $\begin{array}{l}\text { Experience of real-world } \\
\text { work situations in own work } \\
\text { setting and/or mentor's } \\
\text { setting; regular meetings } \\
\text { with mentor to share } \\
\text { thoughts, feelings or } \\
\text { questions related to } \\
\text { professional practice. }\end{array}$ \\
\hline \begin{tabular}{|l} 
Stage 2 \\
Reflexive \\
Observation \\
(Observe)
\end{tabular} & $\begin{array}{l}\text { Online } \\
\text { Community of } \\
\text { Professional } \\
\text { Learning and } \\
\text { Practice }\end{array}$ & Distance & $\begin{array}{l}\text { In an online forum, } \\
\text { description of professional } \\
\text { situations experienced } \\
\text { during Stage } 1 \text {; formative } \\
\text { feedback given to } 3 \text { peers; } \\
\text { reflective synthesis. }\end{array}$ \\
\hline \begin{tabular}{|l} 
Stage 3 \\
Abstract \\
Conceptua- \\
lization \\
(Reflect)
\end{tabular} & $\begin{array}{l}\text { Seminars } \\
\\
\text { Collaborative } \\
\text { Concept } \\
\text { Mapping }\end{array}$ & $\begin{array}{l}\text { Face-to- } \\
\text { face }\end{array}$ & $\begin{array}{l}2 \text { to } 3 \text { whole-day or half-day } \\
\text { seminars per month } \\
\text { (lectures, exercises and } \\
\text { discussions) held at } \\
\text { students' workplace; explicit } \\
\text { links between theoretical } \\
\text { content and work situations } \\
\text { reported in Stage 2. } \\
\text { Creation of an initial } \\
\text { collective concept map } \\
\text { representing knowledge } \\
\text { related to professional } \\
\text { practice; completion and } \\
\text { validation of the map by } \\
\text { each student with mentor } \\
\text { and other experienced } \\
\text { workers at workplace; } \\
\text { sharing and integration of } \\
\text { information into the } \\
\text { collective map; integration } \\
\text { of theoretical knowledge } \\
\text { discussed in seminars in the } \\
\text { map. }\end{array}$ \\
\hline \begin{tabular}{|l} 
Stage 4 \\
Active \\
Experimen- \\
tation \\
(Integrate/Do)
\end{tabular} & Mentoring & F2F & $\begin{array}{l}\text { Meeting with mentor to } \\
\text { discuss new competencies } \\
\text { developed; practice of new } \\
\text { competencies in new real- } \\
\text { world work situations. }\end{array}$ \\
\hline
\end{tabular}

This software enables the creation of node-link diagrams of knowledge, structured according to a knowledge modeling language (MOT) that requires the users to specify not only the label but also the type of each knowledge entity that they include in a knowledge model. Each type of knowledge entity is represented by a different graphic shape (see Figure 2 for an example): (1) rectangles for concepts and rectangles with indented corners for facts (declarative knowledge); (2) ovals for procedures (procedural knowledge) and (3) hexagons for principles (strategic knowledge).

Knowledge entities are linked to each other through arrowed links. Six types of generic links are proposed: composition, regulation, specialization, precedence, input/product and instantiation. When links are selected from the menu and drawn between two knowledge objects, the first letter of the link label is automatically displayed on the link. The representation of links must conform to the MOT "grammar rules" implemented in the software. For example, a 
"specialization link" (equivalent to 'sort of") can only be used between two objects of the same type. Consequently, if the user relates two knowledge entities of different types with the specialization link, the software will automatically display the default link, that is, the best-suited and the most probable according to the knowledge modeling grammar implemented in the software. If the user disagrees with the suggested link, he can right-click on the link and choose another one from the pool of "permitted" links, the invalid links not being clickable. Thus, the MOT tool not only includes a more formalized knowledge representation language than those used in most computer-based concept mapping tools, but it also dynamically guides the knowledge representation activity of the user. Finally, the possibility of creating sub-models for each knowledge entity represented at a certain level of the model is another functionality of the software. ${ }^{3}$

Our previous work indicates that the representational properties of the MOT tool support meaning-making and meaning- negotiation during the collaborative knowledge modeling activity and that, consequently, they can have a beneficial meditational effect on the knowledge construction process [21].

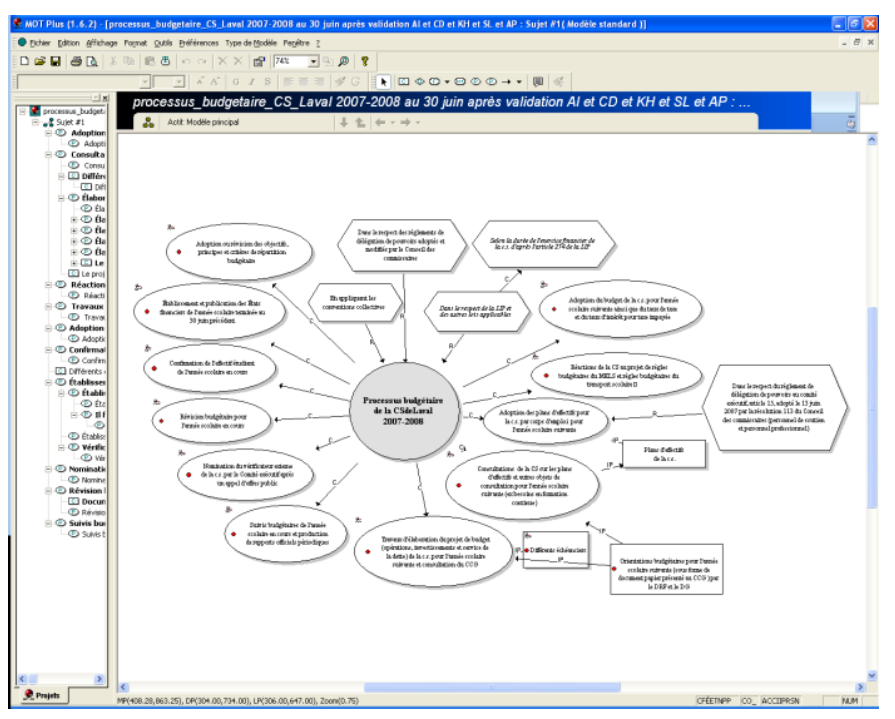

Figure 2. First level of a model constructed by the second group

\section{METHODOLOGY}

A design-based research (DBR) methodology was used in this project. This type of research is described by Wang \& Hannafin [23] as "a systematic but flexible methodology aimed to improve educational practices through iterative analysis, design, development, and implementation, based on collaboration among researchers and practitioners in realworld settings, and leading to contextually-sensitive design principles and theories" (p. 6). The research was qualitative and exploratory. The instructional design process and the research process were closely intertwined within a cyclic and iterative approach [24].

\footnotetext{
${ }^{3}$ For further details on MOT plus: www.cogigraph.com. The software can be downloaded freely for educational use from the section "Products" of this website.
}

The learning model was designed and experimented into the context of a 12-credit graduate program (540 hours) in the field of School Administration offered in a French-Canadian university. Two successive experimentations of the model were performed with small-scale, stable groups of students $(\mathrm{N}=11$ and 12) over a period of 12 and 16 months respectively. They were all in-service teachers aspiring to the school administration profession in the same large School Board. Some of them have obtained school administrator positions during or shortly after the course of the program.

Given that we conducted this project in close partnership with the School Board, we first used the KMS (Knowledge Management System) that was in use at this workplace (DocuShare) to host the study program website. We expected that this would be more amenable for the students who were already familiar with this system. However, realizing that this approach monopolized the time of the professional resource responsible for DocuShare at the School Board, and that we would not be in a position to have just-in-time and complete control of the system to make modifications to the website, we decided that, for the second group, we would use Moodle, which was in use at the university offering the study program.

Data were collected from multiple sources throughout the project, by way of questionnaires for students, mentors and instructors, interviews with students, mentors, instructors and School Board administrators; researchers' observation notes; reports of research group meetings and of a special committee of representatives from each category of participants, messages from the online community of professional learning and practice, concept maps produced, etc. All interview data have been transcribed verbatim and coded, using the qualitative data analysis software N'vivo. In this paper, we will focus on interview and meeting report data which were used to examine potential factors that may have support or hinder retention and academic performance of students.

\section{RESULTS}

First, it must be reported that, among the 23 students enrolled in the training model, there was one involuntary withdrawal due to pregnancy, and that only one student withdrew voluntarily from the program. In this last case, the learner decided to pursue the training through the regular program offered on campus. All of the other students not only successfully completed the 12-credit study program, but they also pursued advanced studies at the same university after the end of this program. Nevertheless, slightly less than half of the students confided that they had considered abandoning the program during the course of the study program; therefore, the drop out risk was potential.

We then looked for factors that may have had an impact on retention and achievement of students attending the type of blended learning model that we proposed in this project. We categorized remarks from students and other participants encompassing a broad spectrum of factors into four main categories: institutional, pedagogical, personal and professional factors. We will present each of these categories of factors by providing a few comments made by the students (translated from French). Such factors can be used as 
guidelines for the design of blended learning models for higher education professional study programs.

\section{A. Institutional factors}

We define institutional factors as those which stem from the university framework that supports the study program (e.g. registration process, university rules, classroom sites, student class grouping, etc.). Participants commented on two of these factors:

Training sites. The blended learning model developed in the project combines activities carried out both online and face-toface on the worksite. The training sites included: (1) school board conference rooms (for face-to-face seminars); (2) mentors' school places where students visited their respective mentor; (3) the study program website (discussions regarding the virtual learning community and access to the training resources), (4) email for personal communication with the instructors outside the face-to-face courses. Most students enjoyed this repartition of training sites: "We were able to reduce the number of courses that required commuting. For me, it was a great asset", mentioned one of the students. The School Board administrators also appreciated that the program was partly offered online: "People work in their individual school building, far from one another [...] If only for that, this type of work [i.e., online discussions] is valuable".

Constitution of the group of students. Participants appreciated the idea of grouping of students working in the same occupational settings; it allowed discussions on common problems in the framework of the learning activities: "We all work at the same school board [...] We are thus concerned with the same issues, the same people and the same problems". They also appreciated the small size of the student group, although they noted that it must be sufficiently large to ensure dynamic discussions in the forum: "I liked the small group that was created. We were about a dozen students, which is neither too small nor too large. I really enjoyed the atmosphere".

\section{B. Pedagogical factors}

The pedagogical factors identified were classified according to whether they concerned a global facet of the model or one of the four instructional strategies integrated in the training model.

\section{1) General pedagogical factors}

In the first category, the following factors were brought up by the participants:

An integrated program approach. The "program approach" adopted in the blended learning model was generally appreciated. Students were initially surprised by its unusual structure (compared to regular university program). Information had to be given to them about it and they needed some time to familiarize themselves with it. Many students spoke about the advantages of the program approach, some of the most salient ones being that it enhanced the linking of theory and practice as well as the interconnection between the different learning activities: "All of the activities were performed simultaneously and all were interconnected. They were thus less fragmented. So, often, what we were doing was related to something else we were doing in another activity. I found this way of integrating the activities really helpful".
Diversity of instructional strategies. One student commented: "It's not always the same thing [like] sitting down for three hours [...] I found it refreshing that this approach offers a little variety".

Explicit linking of theory and practice. "Theoretical knowledge is useless if it is not used. I think that it's actually the integration [of what I learn in the program] into my practice that makes it interesting, that actually helped me integrate my professional knowledge", commented one student.

Learning activities that take into account the diversity of the students' professional practice profiles. As already mentioned, in the context of this project, students were either in-service teachers still teaching full-time or in-service teachers having obtained very recently a school administration position. Some were working at the primary school level and others at the secondary school level. This requires the teaching team to take into account such disparity and make special effort to design learning activities that will be significant and applicable for all.

Professional status of students valued. Students felt that, in this program, their professional status was valued: "I was not simply a number. [...] People believed in what I could bring to the program, while at other universities that I attended, what was important was what the instructors brought. I saw a huge difference that is significant to me". Moreover, a fair balance of rigor and flexibility in how students' requests were taken into account makes students feel they are treated as 'professionals': "They [the instructors] give us certain deadlines, so we must keep up, that's for sure, but they are extremely open [...] We are not treated as students [...], we are considered professionals and this makes me really happy that I chose to attend [this university]".

Quality of the teaching staff. Among the characteristics of a "good" teacher, students brought up availability, enthusiasm, a solid expertise and a diversified work experience in the targeted field of study.

Opportunities for peer interaction and collaboration. For students, communication with their peers allowed not only the creation of a network and reduced feelings of isolation and insecurity regarding a new position, but it also enhanced learning: "I found the discussions with other colleagues interesting. We bonded. We learn through that".

An appropriate training pace. The program pacing was considered too fast for both groups who participated in the study and thus would need to be re-evaluated to be more amenable to students considering they are working full-time professionals: "It's a lot of activities simultaneously. I understand that it's an intensive program [...]. There is much work to do and little time to do it ".

Well-coordinated assignments. Ideally, assignments should be spread out over time and closely linked to work practice: "We often had peak periods where many assignments had to be handed in at the same time, and given a context where you work full time, it was really difficult".

Fast, regular and elaborated feedback on assignments. Constructive feedback from instructors should concern as well the learning process and the learning activities products: "The 
corrections are extremely constructive, I do not feel denigrated. I don't feel judged. They bring up many interesting points and I am lead to bring out the best in me".

A continuous update of the program website. Instructors were not having always enough time to update regularly the website. One student commented on this: "If you want to build up a loyal audience, you've got to have a website that is palatable and up-to-date. Otherwise, people surf elsewhere and they stop visiting your site as it's useless".

Sufficient familiarity with the technological tools used. This is the case for both students and instructors.

2) Pedagogical factors associated to each instructional strategy

Participants' comments also led to more specific factors regarding each of the instructional strategies integrated in the learning model. We list them in the next paragraphs. practice

a) Online community of professional learning and

Well-balanced interdependence among students. As shown in Table 1, all participants had to present in the CPLP every 4 or 8 weeks a professional situation they experienced. They also had to provide feedback to three colleagues and carry out a reflexive synthesis of the received feedback from peers. This type of interdependence implies that all students must actively participate in the discussions; otherwise, a lack of motivation may arise. We noted that such a strong interdependence among students is difficult to apply throughout an entire training program and that it may be possible to determine moments and modality where it may be reduced.

Active animation of discussion by a member of the teaching staff. Students must feel they are not left on their own.

True participation of all students. Students must also feel that all their peers invest authentic efforts to respond to their statements in the CPLP and do not simply "talk to talk".

Adoption of ethical rules. Because professional situations reported in the CPLP are often delicate, everybody must feel sufficiently confident that their colleagues will respect the strict confidentiality of the information provided throughout the online discussions and that they avoid value judgement.

\section{b) Mentoring}

A mentor chosen by the student. The choice of the person who will be the student's mentor should not be imposed to him. The mentor should be an experienced professional who holds (or have held) the professional position targeted and one who is endowed with certain qualities (listening skills, compassion, openness, ethics, enthusiasm, etc.).

Diversified mentoring functions. Support a student can expect from their mentor can concern various aspects of professional practice and career: moral support, counselling, encouragement to persevere, information regarding the job and its reality, broadening of the professional network, etc.

Regular contact with the mentor throughout the program. In this project, there was a minimum of five mandatory meetings to be conducted at a time and place determined by both parties.

Planning modalities and follow ups for the meetings with the mentor. A guide providing a "mentoring contract" form and other forms to plan meetings and note ideas for discussions and reflections was provided to support the mentoring relationship in this project.

Adequate supervision of the mentoring activity by a member of the teaching staff. A minimum of three meetings in groups of three (instructor, mentor and student) was planned in this project during the course of the study program.

A well-prepared and well-supported mentor. The mentor should be familiar with the requirements of the program in which the students they mentor are enrolled and should be trained for the role of mentor. They should be offered incentives in their workplace, such as acknowledging their mentoring function in their task, re-managing their workload to integrate this new function, etc. All mentors should also have opportunities to discuss their mentoring experiences among themselves (for example through faceto-face meetings or an online community of mentors).

\section{3) Collaborative concept-mapping}

Sound choice of the topic that will be "mapped" during the collaborative concept-mapping activity. The topic must be closely linked to the students' professional concerns and it must cover a large span of the targeted knowledge addressed in the program. For example, in Group 2, the topic selected by the instructor for the concept-mapping activity was the "Budgetary Process of a School Board", a topic which allowed students to become familiar with numerous management practices and principles.

Anchoring of the activity in professional practice. For example, in the second cohort, the instructor grouped the students in pairs or in groups of three. Each team had to complete and document a section of an initial collective map developed by the whole group of students during an initial face-to-face meeting. To complete its section, each team had to obtain from various experienced administrators working at the School Board information related to actions, documents, tools, and principles to manage and implement the budgetary process at the School Board. After a second meeting, in which all of the collected information was shared, students had to validate the collective map with their respective mentors. Finally, a last meeting took place to discuss all of the collected information and to complete the map according to theoretical considerations discussed in the face-to-face seminars attended throughout the study program. The final model included 22 sub-models distributed on 3 levels, 42 concepts, 51 procedures, and 95 
principles. Anchoring the activity in the context of the students' professional practice was an effective component for their learning: "I had been involved in the budgets for the last three years [...] and I didn't get it. When I started using that software [MOT Plus], I really understood how the budget process works. Moreover, this activity had an impact on our professional development: it automatically sets us up in the real-life of the professional practice in our work setting!"

Sufficient time to become familiar with the conceptmapping technique and tool. It seems that initially, the software MOT and its language were perceived as rather "complicated" by students, although in fact, they got used to it rather quickly.

\section{a) Face-to-face seminars}

Seminars spaced out in time. They should neither be too close together nor too far apart throughout the study program. A new seminar was planned about every month and most of them lasted a whole day.

Integration of various pedagogical strategies to seminars. Some students indicated that seminars should include not only instructor' lectures, but also face-to-face discussions among students and instructor. Different practical exercises were also proposed to students during these seminars.

\section{Personal factors}

Numerous personal factors that could have a potential impact on academic perseverance or success were brought up by participants interviewed:

Students' health and that of their relatives. One student said: "I was sick [...] I fell behind in the workload [...] I had to get an extension from an instructor [...]. Of course, the thought of dropping out of the program crossed my mind because of that situation".

Past grades. These would serve as indicators for students to estimate their future academic success and, when grades are good, to motivate themselves to pursue their studies: "I took a course at the university last year and I got a really good mark, so it was really encouraging".

Experience with studies at the university level. Students who already experienced studying at the university level are more aware of the type of work they are generally asked to carry out at this level. Some noted that this contributed to their academic success: "I am used to this type of work. I think this makes it much easier".

Strong personal desire to learn and succeed. Here is one typical comment illustrating this factor: "I always want to improve and learn new stuff" .

Personal efforts devoted by the student to her/his studies. Students who mentioned this factor made comments like this one: "I really worked hard!".

Self-discipline and self-organization skills. For example, one student said: "We had to be well-disciplined and stick to a schedule".
Support from friends and family. "People at home were behind me", commented one student. It seems that being a single parent was a factor that added certain challenges which were quite significant for reconciling studies, work and family: "I'm a single mother; of course, there is nobody home when I'm not there".

Career aspirations and self-perceived aptitudes for the profession. These include the students' desire to take up new professional challenges and the feeling of being "naturally" predisposed for the targeted position. Students had the opportunity to carry out such functions during the program, which allowed them to confirm their career aspirations: "I realized that this type of work renewed my motivation at work and made me enjoy my job".

Perceived need to be trained in order to perform in the targeted position. Even though students were experienced workers in the teaching sector, some noted that for being successful in the targeted professional position (school administrator), they really need to acquire new professional competencies: "I figure that we can't start a school management job with all of the competencies on the first day. [...] Certain competencies are prerequisites, but others must be learned".

Perceived direct utility of the training for professional practice. Some students mentioned that they need to feel that what they learn in the study program can be applied directly in their professional practice: "When I feel that I get benefits from the study program in my work practice, it's easier for me to invest time and energy in it. However, when we feel that it's more or less useful, that we just need to 'get through' the program, it becomes very tedious".

\section{Professional factors}

Finally, three factors classified under the category "professional factors" were mentioned by students as potentially influencing academic retention and success:

Legal obligation of completing a diploma to obtain a position or stay in the profession. This was the case in the two groups of students who participated in this study, who had five years to complete at least 30 credits of university courses. If obligation is surely a perseverance factor, we should also be aware that it could also trigger a certain level of aversion towards the study program and consequently have an impact on student success: "I must go through this if I want to keep the job I love [...]. The fact that it is a formality, that it is mandatory and that we must jump through the hoops to continue working really takes a toll on the level of satisfaction".

Facilitative conditions for conciliating work, study and family life. The difficulty of conciliating work, study and family was a challenge that was often brought up by participants. Here is a typical comment from a student on the topic: "Our workload already overloads on our private lives over the weekend and then, with university assignments and studying to do on top of that, it can become very demanding." Handling schoolwork and professional work seems particularly difficult at the beginning of one's career: "I guess it may be easier to 
combine both if you're a school administrator with many years of experience. However, I am overloaded at work and on top of that, I have homework to $d o^{\prime \prime}$. Some of the measures they identified that the institutions could set up include allowing release time for face-to-face courses and additional staff to replace employees when they are absent for training purpose;

Support from colleagues and supervisors. This support can take the form of moral support, reduction of the workload when assignments are due, etc.: "I think the fact that we are enrolled in a training program makes the management more lenient towards us. They know that we are in training, they want to help us and they are always available".

E. Synthesis of Potential Factors of Retention and Achievement in Higher Education Professional Study Programs

Table 2, at the end of this article, sums up the set of potential factors of retention and academic success identified during this project conducted in the context of a study program that was delivered with a blended learning approach to students already involved in a professional career.

\section{CONCLUSION}

The results of this study suggest that universities should develop new pedagogical models in order to promote retention and academic success for students who are already engaged in a professional career and who attend university programs to develop their professional competencies. The blended, experiential, and situated learning model developed in this project seems to be an avenue worth further exploration. The model amalgamates several instructional strategies at the program level. Throughout the entire program, students are invited to: (1) discuss online of situations and concerns drawn from their professional practices, (2) use an object-typed knowledge modeling software tool to elaborate graphical knowledge models representing practical as well as theoretical knowledge related professional domain of practice, (3) share ideas and knowledge with experienced professionals, (4) attend a series of face-to-face seminar. The blended learning model does not require a complex technological environment: a single program website can be developed in an existing e-learning platform. All members of the teaching team can contribute to the revision of the website on a continuous basis.

This exploratory study of potential factors that may hinder or favour retention and academic achievement in students who experimented the proposed blended learning model led us to identify over 40 factors, which we classified into four main categories: institutional, pedagogical, personal and professional. Results indicate that institutional, pedagogical and professional factors must be given special attention if we wish to retain students and promote achievement in professional university programs.

Further research is needed to confirm and weight the differential effects of these factors. Also, we need to verify whether the model, or at least part of it, can be realistically applied with larger groups of students and in other types of study programs. We must also evaluate its impact on retention and academic achievement with different types of quantitative and qualitative measures. Various research methodologies (including qualitative and experimental studies) should be used to contribute to these lines of research.

\section{ACKNOWLEDGMENT}

This project was funded by the Fonds de recherche sur la société et la culture (FQRSC) [Quebec Societal and Cultural Research Fund].

\section{REFERENCES}

[1] AUCC (Association of Universities and College of Canada). (2005). People and Ideas! Why Higher Education is a Cornerstone of Productivity. [Electronic Version]. Retrieved on October 2005, 2009 from Barab, S. A., Kling, R., \& Gray, J. H. (Eds.). (2004). Designing for virtual communities in the service of learning. Cambridge: Cambridge University Press.

[2] UNESCO (2005). Towards Knowledge Societies. UNESCO World Report. Paris: UNESCO Publishing. [Electronic Version]. Retrieved on March 15, 2009 from http://unesdoc.unesco.org/images/0014/001418/141843e.pdf

[3] Tinto, V. (1992). Student Attrition and Retention. In C. R. Burton \& G. Neave (Eds.), The Encyclopedia of Higher Education (Vol. 3). New York: Pergamon Press.

[4] Berger, J., \& Braxton, J. (1998). Revising Tinto's Interactionist Theory of Student Departure through Theory Elaboration. Research in Higher Education, 39, 103-119.

[5] Hoffman, H. F. (2000). A Qualitative Analysis of Technical Nontraditional Student College Attrition. Frontiers in Education Conference, 30th Annual Conference FIE, Volume 1, 1-6.

[6] Kasworm, C. (2003). Setting the Stage: Adults in Higher Education. New Directions for Student Services, 102(Summer), 3-10.

[7] Sandler, M. E. (2000). Career Decision-Making, self-efficacy, perceived stress and an integrated model of student persistence : A structural model of finance, attitudes, behavior and career development. Research in Higher Education, 41(5), 537-580.

[8] Osborne, M., Gallacher, J., \& Crossan, B. (2004). Researching Widening Access to Lifelong Learning: Issues and Approaches in International Research. London: Routledge.

[9] Vermetten, Y., Vermunt, J. D., \& Lodewijks, H. G. (2003). Powerful Learning Environments? How University Students Differ in Their Response to Instructional Measures. Learning and Instruction,12(3), 263-284.

[10] Brown, S. M. (2002). Strategies that contribute to nontraditional/adult student development and persistence. PAACE Journal of LifelongLearning, 11, 67-76.

[11] Voorhees, R. A. (2001). Competency-Based Learning Models: A Necessary Future. New Directions for Institutional Research, 110(1), 513.

[12] Bonk, C. J., \& Graham, C. R. (Eds.). (2006). Handbook of Blended Learning. San Francisco: John Wiley \& Sons.

[13] Brown, J. S., Collins, A., \& Duguid, P. (1989). Situated cognition and the culture of learning. Educational Researcher, 18(1), 32-42.

[14] Kolb, D. A. (1984). Experiential learning : Experience as the source of learning and development. New Jersey: PTR Prentice Hall.

[15] Barab, S. A., Kling, R., \& Gray, J. H. (Eds.). (2004). Designing for virtual communities in the service of learning. Cambridge: Cambridge University Press.

[16] Wenger, E. (1998). Communities of practice: Learning, meaning, and identity. Cambridge, UK: Cambridge University Press.

[17] Novak, J. D. (1998). Learning, creating and using knowledge: Concept maps as facilitative tools in schools and corporations. Mahwah, NJ: LEA.

[18] Lave, J., Wenger, E. (1991). Situated learning: Legitimate peripheral participation. New York: Cambridge University Press.

[19] Schön, D. A. (1983). The reflective practitioner: How professionnals think in action. New York: Basic Books. 
[20] Basque, J., Pudelko, B. (in press). Modeling for Learning. In Paquette, G., Visual Knowledge and Competency Modeling - From Informal Learning Models to Semantic Web Ontologies. Hershey, PA: IGI Global.

[21] Basque, J., Pudelko, B. (2009). Intersubjective Meaning-Making in Dyads Using Object-Typed Concept Mapping In P. L. Torres \& R. C. V. Marriott (Eds.), Handbook of Research on Collaborative Learning Using Concept Mapping (pp. 180-206): IGI Global.

[22] Paquette, G. (2002). Modélisation des connaissances et des compétences. Sainte-Foy (Québec): Presses de l'Université du Québec.

[23] Wang, F., \& Hannafin, M. J. (2005). Design-based research and technology-enhanced learning environments. Educational Technology Research \& Development, 53(4), 5-23.

[24] Basque, J., Nault, T., St-Pierre, M., Toussaint, P., Brunet, L., Pudelko, B., et al. (2009). A Blended, Experiential and Situated Learning Model for Vocational Higher Education Programs. Paper presented at the AERA 2009.
TABLE II. POTENTIAL FACTORS OF ACADEMIC RETENTION AND ACHIEVEMENT FOR FULL-TIME WORKING STUDENTS

ATTENDING A HIGHER EDUCATION PROFESSIONAL STUDY PROGRAM

\section{A - Institutional factors}

1. Combination online and face-to-face activities (if possible, face-to-face activities being done in the workplace setting)

2. Constitution of stable groups of students who share same or similar jobs and workplaces

3. Small-size groups of students, but sufficiently large to ensure dynamic communication among students (below 20 students)

\section{B - Pedagogical factors}

General pedagogical factors :

4. An integrated program approach.

5. Diversity of instructional strategies.

6. Explicit linking of theory and practice.

7. Learning activities that take into account the diversity of the students' professional practice profiles.

8. Professional status of students valued.

9. Quality of the teaching staff.

10. Opportunities for peer interactions and collaboration.

11. An appropriate training pace.

12. Well coordinated assignments.

13. Fast, regular and elaborated feedback on assignments.

14. A continuous update of the program website.

15. Sufficient familiarity with the technological tools used (students and instructors).

Online community of professional learning and practice:

16. Well-balanced interdependence among students.

17. Active animation of online by a member of the teaching staff.

18. True participation of all students.

19. Adoption of ethical rules.

\section{Mentoring:}

20. A mentor chosen by the student.

21. Diversified mentoring functions.

22. Regular contact with the mentor throughout the entire study program.

23. Planning meetings with the mentor and follow ups.

24. Adequate supervision of the mentoring activity by a member of the teaching staff.

25. Well-prepared and well-supported mentors.

Collaborative concept-mapping:

26. Sound choice of the topic that will be "mapped" during the collaborative concept-mapping activity.

27. Anchoring of the activity in professional practice.

28. Sufficient time to become familiar with the selected concept-mapping technique and tool.

Face-to-face seminars:

29. Seminars well-spaced out in time (not too frequent, nor too far apart).

30. Integration of various pedagogical strategies to seminars (not just lectures).

\section{Personal factors}

31. Students' health and that of their relatives.

32. Past student grades.

33. Experience with studies at the university level.

34. Strong personal desire to learn and succeed.

35. Personal efforts devoted by the student to her/his studies.

36. Self-discipline and self-organization skills.

37. Support from friends and family.

38. Career aspirations and self-perceived aptitudes for the profession.

39. Perceived need to be trained in order to perform in the targeted position.

40. Perceived direct utility of the training for professional practice.

\section{Professional factors}

41. Legal obligation of completing a diploma to obtain a position or stay in the profession.

42. Facilitative conditions for conciliating work, study and family life.

43. Support from colleagues and supervisors. 